\title{
Imaging Features of Rhinoplasty
}

\author{
C.J. Schatz and D.T. Ginat
}

\section{ABSTRACT}

SUMMARY: Cosmetic rhinoplasty encompasses a diverse group of procedures, including alteration of the radix, nasal dorsum, nasal tip, and nasal base; premaxillary augmentation; septoplasty; and combinations thereof. Similarly, many different types of grafts and alloplastic materials can be used in cosmetic rhinoplasty, such as cartilage, bone, silicone, porous polyethylene, expanded polytetrafluoroethylene, and calcium hydroxylapatite. Complications of rhinoplasty that can be observed on imaging include retained metallic surgical instrument fragments, infection, implant extrusion, nerve impingement by implants, nasal valve collapse, and implant deformity. Knowledge of the basic surgical procedures and potential complications of cosmetic rhinoplasty is important for adequately interpreting postoperative radiologic imaging studies.

ABBREVIATION: $\mathrm{K}$-wires $=$ Kirschner wires

C osmetic rhinoplasty consists of surgically modifying portions of the nose to ameliorate its appearance, while maintaining its function. The procedure is the second most commonly performed cosmetic surgery, with 243,772 cases recorded in 2011 in the United States. ${ }^{1}$ Thus, it is not uncommon to encounter the sequelae of rhinoplasty on head and neck imaging. The imaging characteristics of the different types of rhinoplasty, augmentation materials, and associated complications are reviewed.

\section{Types of Surgery}

Rhinoplasty can be performed for cosmetic or functional purposes. The surgery can be classified as primary (performed for the first time) or secondary (revision), in which patients return for additional surgery to address over-resection, under-resection, delayed effects of shrink-wrapping, functional problems, and other complications. ${ }^{2-5}$ Furthermore, rhinoplasty can be performed via external (open) or endonasal (closed) approaches. Ultimately, rhinoplasty encompasses a diverse group of procedures, including the following types of techniques:

From the Department of Radiology (C.J.S.), Beverly Tower Wilshire Advanced Imaging, University of Southern California Keck School of Medicine, Los Angeles, California; and Department of Radiology (D.T.G.), Massachusetts General Hospital, Harvard Medical School. Boston, Massachusetts.

Please address correspondence to Daniel T. Ginat, MD, MS, Massachusetts General Hospital, 55 Fruit St, Boston, MA 02114; e-mail: ginatd01@gmail.com

-- Indicates open access to non-subscribers at www.ajnr.org

http://dx.doi.org/10.3174/ajnr.A3443
- Radix modification consists of reduction versus augmentation (Fig 1). The radix is typically altered in harmony with the nasal dorsum and tip. A rasp or osteotome can be used for reduction, while various implants and grafts can be used for augmentation. $^{2,6}$

- Nasal dorsum surgery consists of dorsal hump reduction versus augmentation. Reduction surgery consists of excising excess osteocartilaginous septum by using a rasp or chisel. ${ }^{2,7}$ The resected tissue can sometimes then be used as a columella strut, tip graft, or for radix augmentation. ${ }^{2}$ On the other hand, augmentation can be performed with autografts or alloplastic implants (Fig 2).

- Tip modification procedures include elevation by using a columellar strut, shield or tip grafts, volume reduction via cartilage trimming, and altering the definition and projection (Fig 3). ${ }^{7}$

- Nasal base surgery includes narrowing the wide columella, wedge resection, nostril sill resection, rim excision, alar reshaping with a graft, and columella excision or grafting. ${ }^{2}$ Augmentation of the columella is often performed in conjunction with nasal dorsum augmentation and can be accomplished by using L-strut implants (Fig. 4)

- Lateral osteotomy consists of creating fractures of the nasal processes of the maxillae and shifting the lateral nasal walls to narrow a wide nose, widen a narrow bony pyramid, straighten a deviated nose, and close an open roof deformity. ${ }^{8}$ The osteotomy sites are initially visible on CT as radiolucent defects and perhaps mild displacement of the nasal processes (Fig 5). Osteotomies are sometimes performed as a greenstick-type frac- 


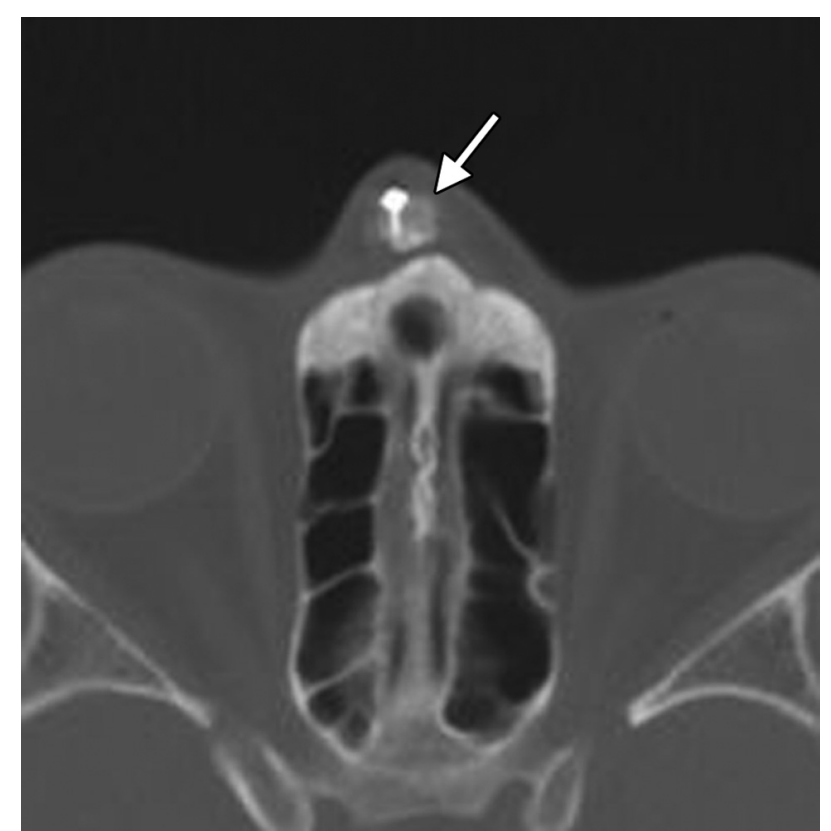

FIG 1. Radix implant. Axial CT image shows a bone graft positioned at the level of the nasal radix, secured by a metal plate and screws (arrow).

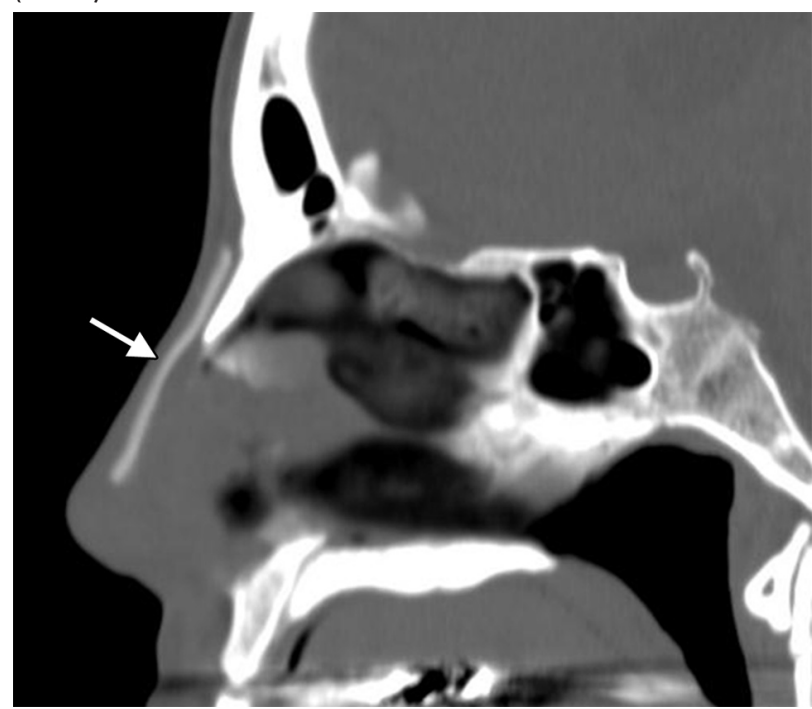

FIG 2. Dorsal nasal implant. Sagittal CT image shows a hyperattenuated expanded polytetrafluoroethylene nasal dorsum implant (arrow).

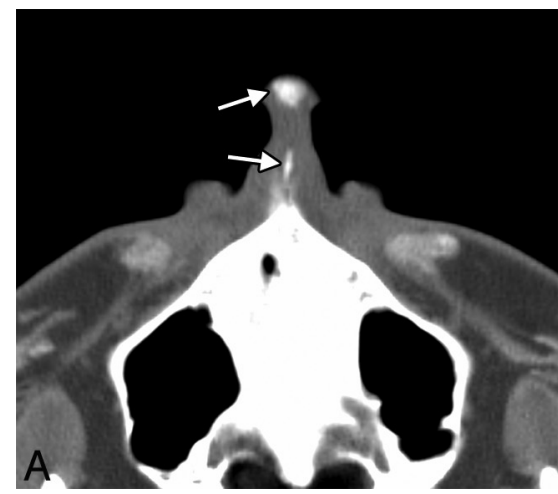

ture, resulting in stable bone stumps. ${ }^{9}$ The osteotomies generally heal by 6 months, and remodeling can be observed on CT. ${ }^{10}$

- Premaxillary augmentation can be performed as an adjunct to rhinoplasty to treat an excessively deep infranasal sulcus (premaxillary underprojection) and acute nasolabial angle. This can be accomplished by using autografts of implants positioned in the midline just inferior to the anterior nasal spine of the maxilla (Fig 6). ${ }^{11,12}$ The implants can have a linear or bat-wing configuration. ${ }^{12}$

Rhinoplasty can also be performed in conjunction with septoplasty for correcting concurrent nasal septal deviation (septorhinoplasty) and other cosmetic facial interventions to optimize esthetic balance. ${ }^{13}$ Septoplasty usually appears as a straight and thin septum without spurs on imaging (Fig 7).

\section{Types of Graft and Implant Materials}

A variety of materials are available for rhinoplasty, including autografts and alloplastic materials. Graft materials include bone and cartilage, which can be harvested from septal cartilage, auricular conchal cartilage, costal cartilage, calvarial bone, iliac crest bone, and costal bone and acellular dermal graft (AlloDerm; BioHorizons, Birmingham Alabama). ${ }^{14-17}$ "Turkish Delight " is a unique graft composed of diced cartilage mixed with a small amount of blood and wrapped in Surgicel (Ethicon, Raleigh North Carolina). ${ }^{18}$ Overgrafting is often intentionally performed with certain graft materials, especially AlloDerm, to compensate for eventual resorption and atrophy. ${ }^{14}$ However, cartilage transplanted with perichondrium has been shown to induce growth of new cartilage or bone. ${ }^{19}$ On CT, cartilage appears as soft-tissue attenuation, though calcification or ossification may form, rendering the graft hyperattenuated. ${ }^{20}$ The cortex of bone grafts is hyperattenuated on CT, though the size and attenuation can diminish with time with resorption of the graft. ${ }^{20}$ Bone grafts may contain marrow elements, which have softtissue attenuation on CT and can display fat signal characteristics on MR imaging. ${ }^{20}$

Alloplastic implants used in facial cosmetic surgery include silicone (Silastic; Dow Corning, Auburn, Michigan), polyamide mesh (Supramid; S. Jackson, Alexandria, Virginia), polyethylene tetraphthalate mesh (Mersilene; Ethicon), expanded polytetrafluoroethylene (Gore-Tex; W.L. Gore \& Associates, Newark, Delaware), and high-attenuation porous polyethylene (Med-

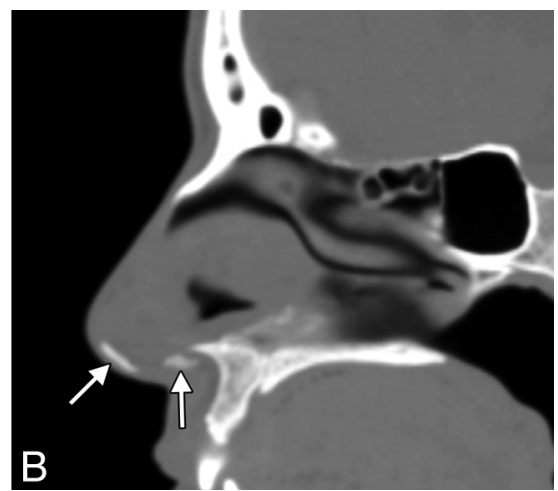

FIG 3. Tip augmentation with a columellar strut graft. Axial $(A)$ and sagittal $(B) C T$ images show hyperattenuated grafts within the infratip lobule and columella (arrows). 


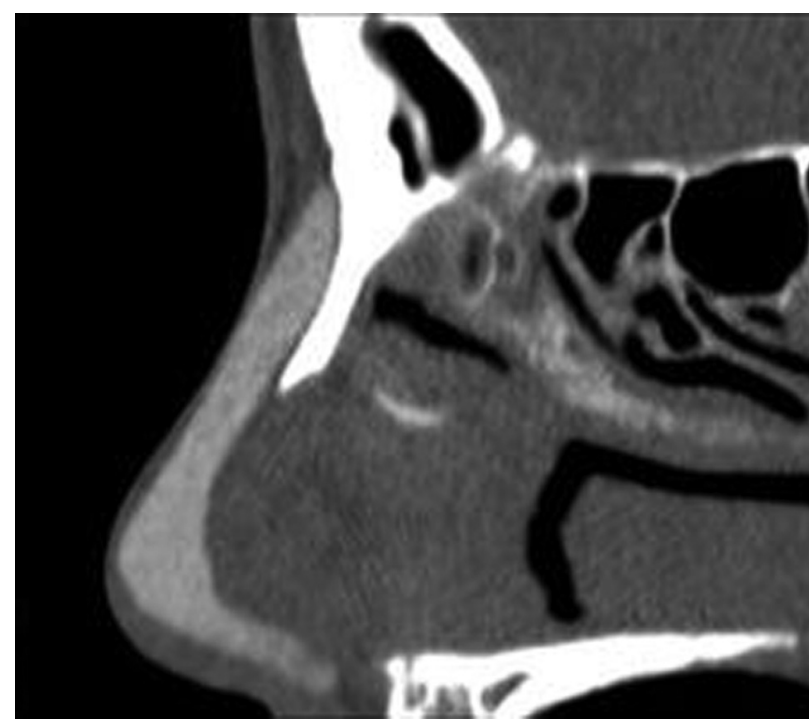

FIG 4. Silicone L-strut implant. Sagittal CT image shows the hyperattenuated L-shaped Silicone implant extending from the nasal dorsum to the columella.

por; Stryker, Mahwah, New Jersey). ${ }^{14,21-25}$ Silicone and expanded polytetrafluoroethylene are similarly hyperattenuating, intermediate in attenuation between soft tissue and bone. ${ }^{20}$ On the other hand, high-attenuation porous polyethylene is hypoattenuating with attenuation intermediate between soft tissue and fat, and it has intermediate signal on $\mathrm{T} 1$ and $\mathrm{T} 2 \mathrm{MR}$ imaging sequences. ${ }^{20}$ The material can appear to enhance due to fibrovascular in-growth.

Filler agents, such as calcium hydroxylapatite (Radiesse; Merz Aesthetics, San Mateo, California), can be used for minimally invasive cosmetic rhinoplasty or to modify prior rhinoplasty. ${ }^{26,27}$ The fillers can be injected by using a linear, threading, fanning, or cross-hatching technique. ${ }^{27}$ Calcium hydroxylapatite displays high attenuation on CT (Fig 8). ${ }^{28}$

Metallic Kirschner wires can be used for restoration of an im-

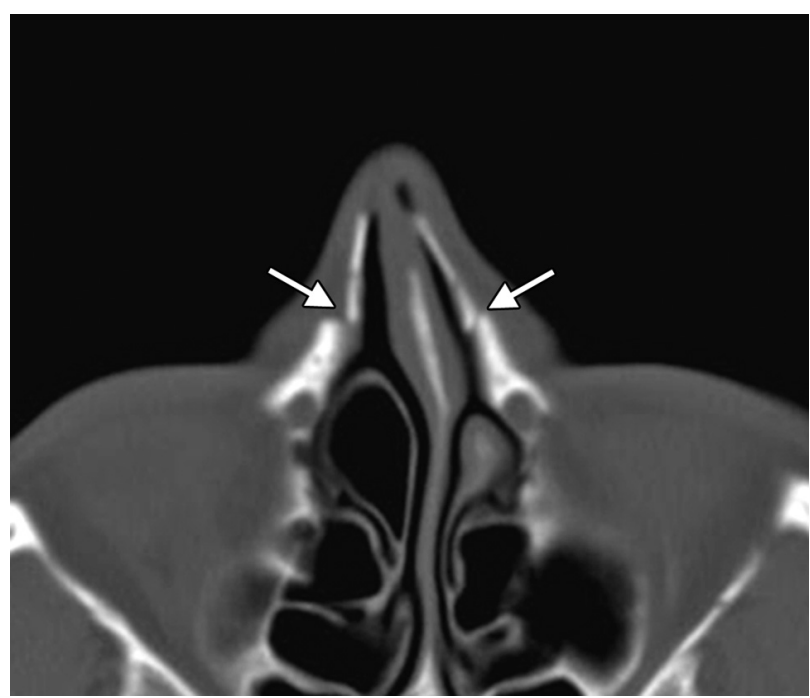

FIG 5. Lateral osteotomy. Axial CT image shows defects in the bilateral nasal processes of the maxillae (arrows). The lateral nasal walls are displaced medially (in-fractures).

pacted nasal pyramid, fixation of intraoperative nasal septum fractures, and stabilization of costal cartilage grafts. ${ }^{29-31} \mathrm{~K}$-wires can be implanted in the nasal dorsum, columella, or both because in an L-strut configuration, a wire is positioned along the dorsum (Fig 9). The columellar K-wires are typically inserted into a maxillary drill hole in the area of the nasal spine, adjacent to the incisive canal.

\section{Complications}

Complications of rhinoplasty that can be found on imaging include retained metallic surgical instrument fragments, infection, implant extrusion, cranial nerve impingement by implants, nasal valve collapse, and implant deformity. ${ }^{21}$

Surgical paraphernalia used in rhinoplasty are rarely retained during surgery. This can occur, for instance, as a result of os-
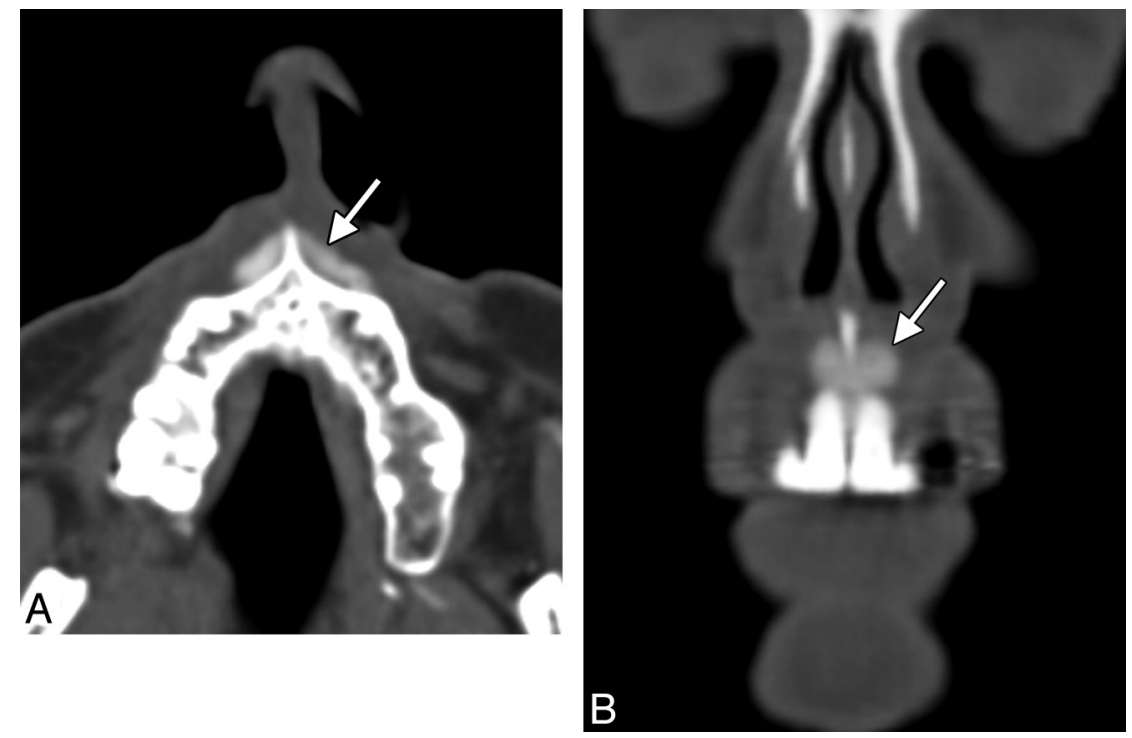

FIG 6. Premaxillary implant. Axial $(A)$ and coronal $(B) C T$ images show a hyperattenuated strip of silicone (arrows) positioned in the midline anterior to the nasal spine of the maxilla. 


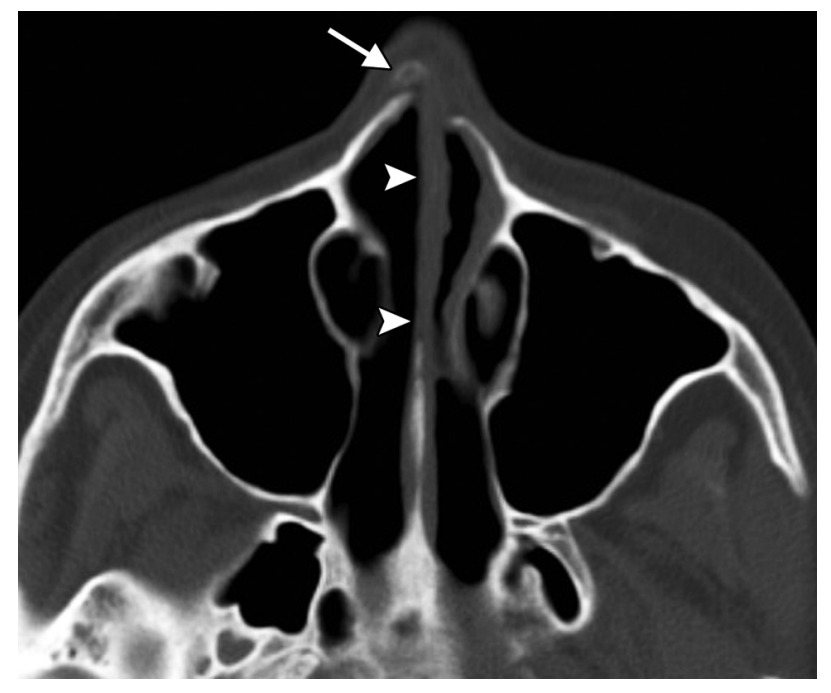

FIG 7. Septorhinoplasty. Axial CT image shows a very straight and thin nasal septum (arrowheads). A bone graft is present within the nasal dorsum (arrow).

teotome breakage during nasal osteotomy, leaving behind a fragment that can be difficult to find intraoperatively. However, ra- diographs can readily confirm and localize retained metallic foreign bodies (Fig 10).

Infection is the most common objective complication of rhinoplasty and can occur early or late postoperatively. ${ }^{32}$ This complication is more common with alloplastic implants than autografts. ${ }^{14}$ The postoperative infections most often remain localized to the skin and subcutaneous tissues of the nose but occasionally extend intracranially or result in generalized septicemia. ${ }^{32}$ MR imaging or CT can be used to delineate the extent of infections, which can appear as fluid collections, sclerosis and enhancement of osseous structures, and soft-tissue inflammatory changes (Fig 11). Infection predisposes to skin ulceration and implant extrusion (Fig 12). ${ }^{33,34}$

Lip dysesthesia can occur after certain types of rhinoplasty, but this is expected to resolve within 6 weeks without functional sequelae. ${ }^{35}$ However, inadvertent drilling and insertion of columellar K-wires into the incisive canal can lead to dysesthesia in the distribution of the nasopalatine nerve. This complication can be observed on CT (Fig 13).

Various types of deformities have been described following cosmetic rhinoplasty, including nasal valve collapse, inverted-V deformity, saddle nose deformity, open roof, stairstep deformity,
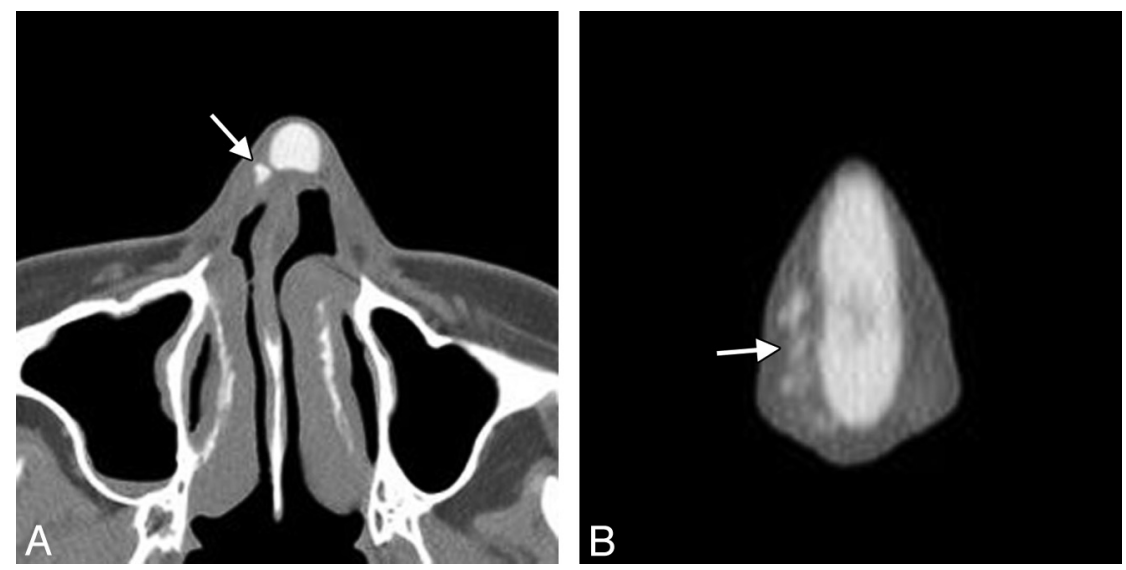

FIG 8. Rhinoplasty with filler. Axial (A) and coronal (B) CT images show hyperattenuated hydroxylapatite filler (arrows) to the right of the Silastic nasal dorsum implant. Note the deviated nasal septum.
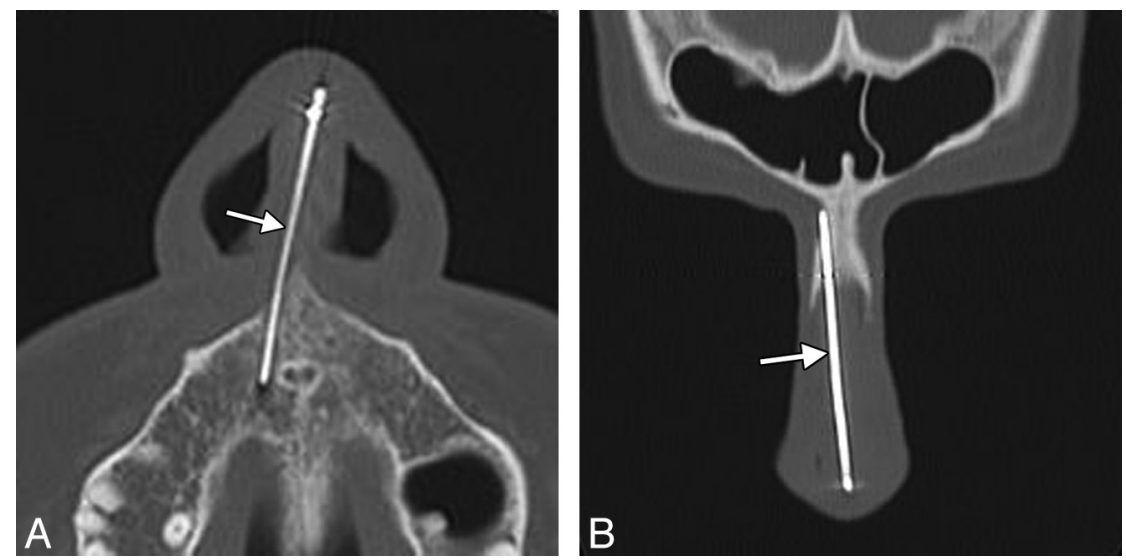

FIG 9. Kirschner wire strut. Axial $(A)$ and coronal $(B) C T$ images show a metallic wire (arrow) extending along the nasal dorsum and nasal base, where it inserts into the maxilla, lateral to the incisive canal. 

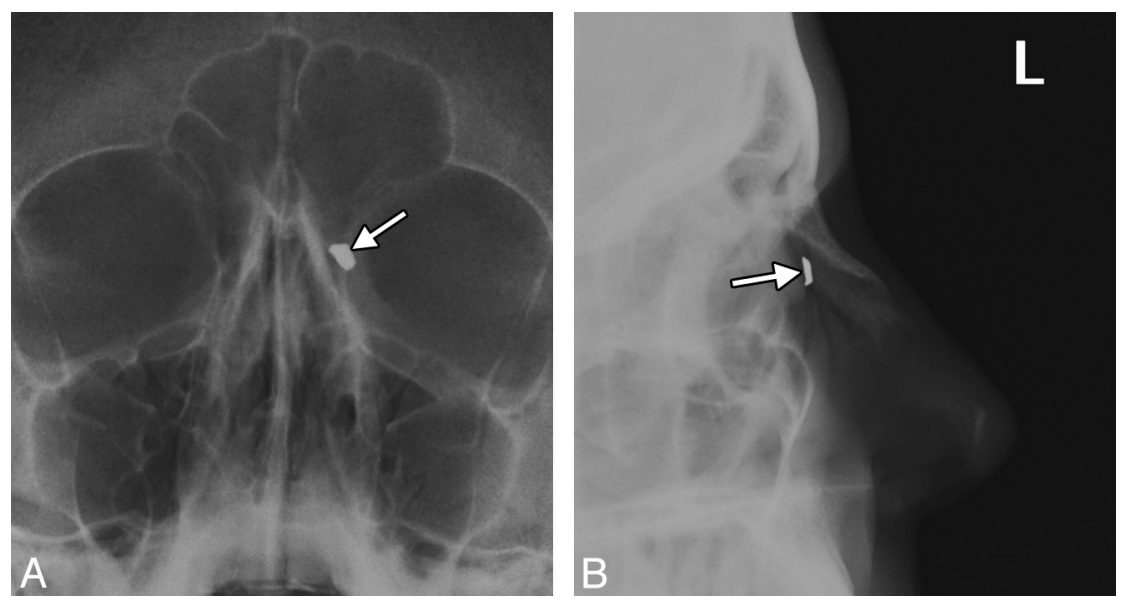

FIG 10. Retained osteotome fragment. Frontal $(A)$ and lateral $(B)$ radiographs show the retained metallic fragment (arrows) at the left lateral osteotomy site. Note the nasal-tip bone graft.

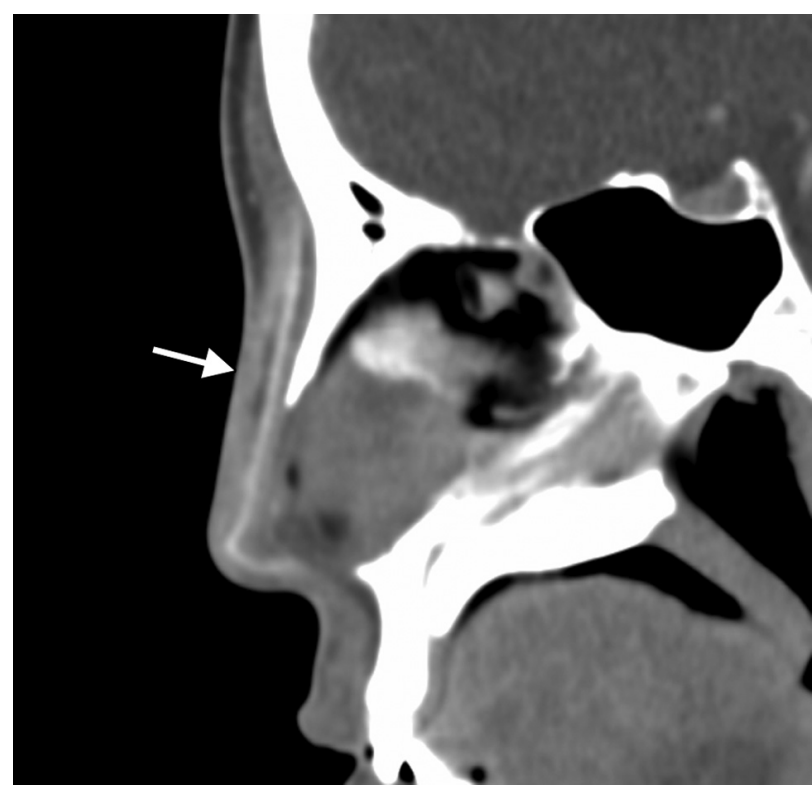

FIG 11. Implant infection. Sagittal postcontrast CT image shows a small fluid collection and associated inflammatory changes (arrow) in the nasal dorsum surrounding the implant.

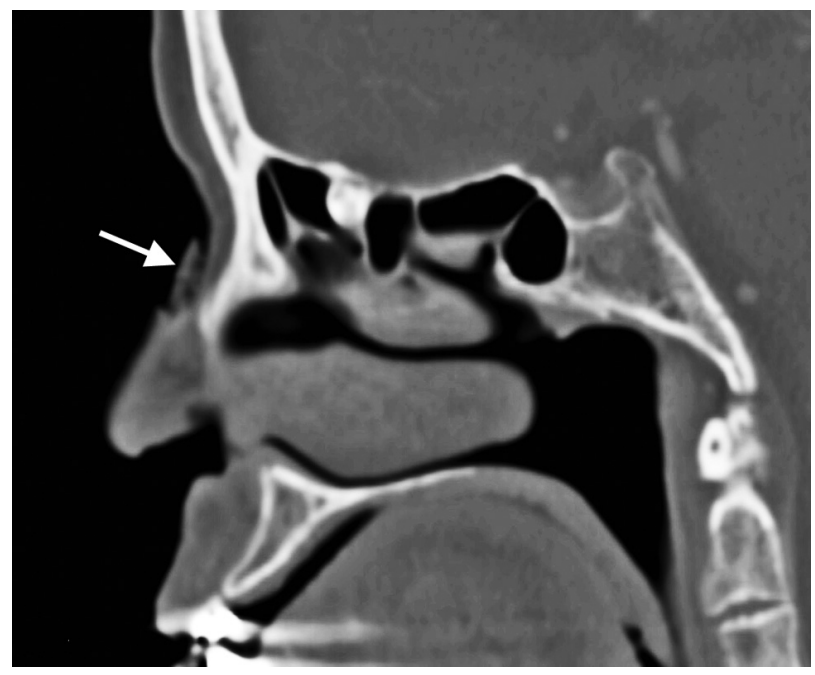

FIG 12. Implant extrusion. Sagittal CT image shows a porous polyethylene dorsal nasal implant (arrow) projecting through a cutaneous defect.

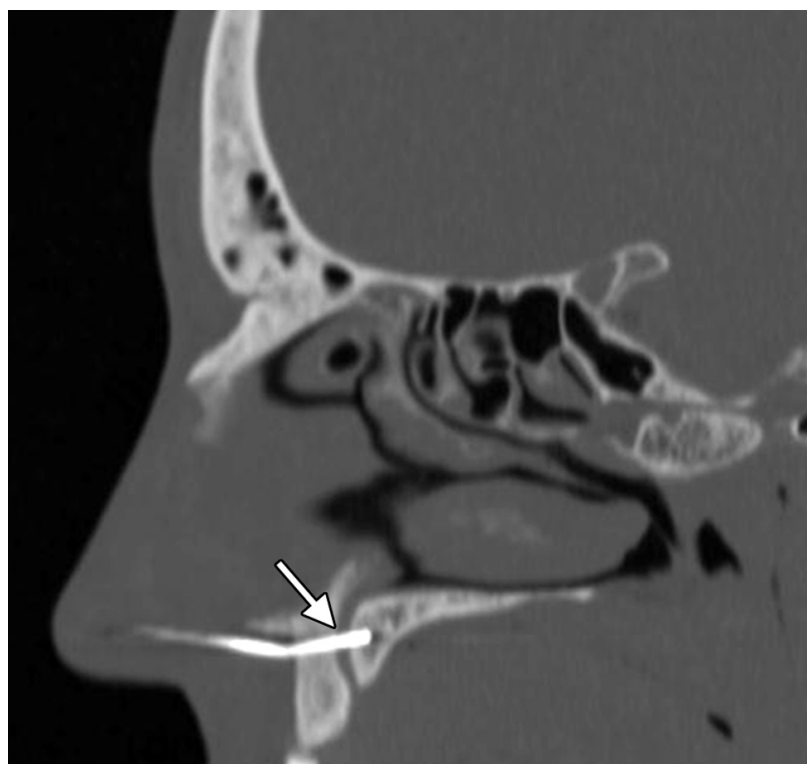

FIG 13. Nerve impingement. The patient presented with dysesthesias in the maxillary nerve distribution after rhinoplasty. Sagittal CT image shows that the $\mathrm{K}$-wire traverses the incisive canal at the expected location of the nasopalatine nerve (arrow).

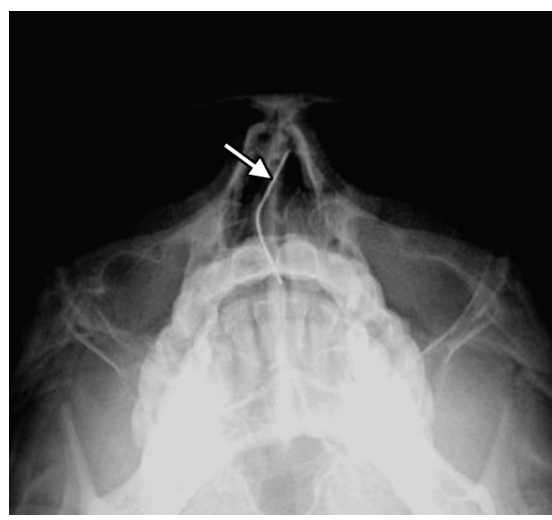

FIG 14. Deformed K-wire. The patient presented with trauma to the nose. Submentovertex radiograph shows a bend in the $\mathrm{K}$-wire (arrow). 


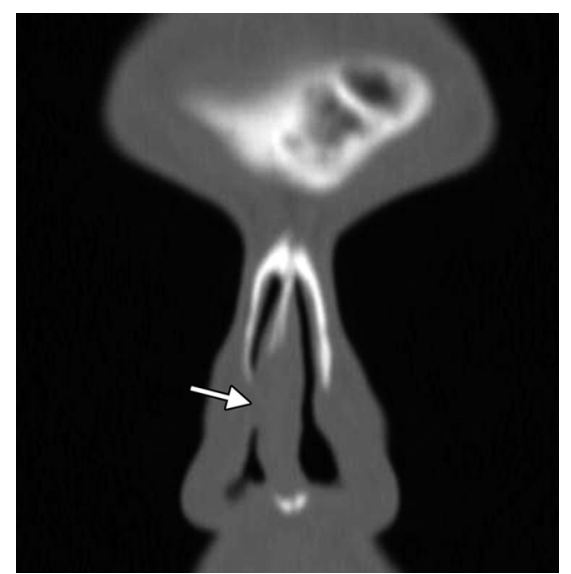

FIG 15. Nasal valve collapse. Coronal CT image shows stenosis of the right nasal valve (arrow). The left nasal valve remains patent

hourglass deformity following dorsal hump surgery, and shrinkwrap effect of the soft tissues after nasal tip surgery. ${ }^{13,36-38}$ Postoperative deformity can also result from warping of grafts, particularly undiced cartilage grafts. ${ }^{39}$ Furthermore, trauma can compromise the structural integrity and alignment of grafts and implants (Fig 14).

Postoperative nasal valve collapse can lead to dynamic or static obstruction and is evidenced by a decreased nasal valve angle, which is normally $10^{\circ}-15^{\circ} .^{36,38,40}$ The nasal valve angle can be more reliably determined on CT than via endoscopic methods (Fig 15). ${ }^{41}$ Furthermore, nasal-base-view reformatted CT images obtained in a plane perpendicular to the anterior aspect of the estimated acoustic axis are more accurate than traditional coronal CT images for measuring nasal valve angles. ${ }^{40}$ Spreader grafts and suture techniques, splay grafts, alar batten grafts, lateral crural extension grafts, and lateral alar suspension can be used to correct this deformity. ${ }^{13,42}$

\section{CONCLUSIONS}

A wide variety of techniques and augmentation materials are used for cosmetic rhinoplasty. Familiarity with the expected alterations, and complications from rhinoplasty is essential for satisfactory interpretation of postoperative imaging.

Disclosures: Charles Schatz-UNRELATED: Expert Testimony: various attorneys, Comments: 2-3 times per year, no conflict of interest, Stock/Stock Options: unrelated investments/retirement plan.

\section{REFERENCES}

1. 2011 Cosmetic Plastic Surgery Statistics. American Society of Plastic Surgeons. http://www.plasticsurgery.org/Documents/news-resources/statistics/2011-statistics/2011-cosmetic-procedures-trends-statistics.pdf. Accessed September 1, 2012

2. Bagheri SC. Primary cosmetic rhinoplasty. Oral Maxillofac Surg Clin North Am 2012;24:39-48

3. Bagheri SC, Khan HA, Jahangirnia A, et al. An analysis of 101 primary cosmetic rhinoplasties. J Oral Maxillofac Surg 2012;70:902-09

4. Cuzalina A, Qaqish C. Revision rhinoplasty. Oral Maxillofac Surg Clin North Am 2012;24:119-30

5. Bracaglia R, Fortunato R, Gentileschi S. Secondary rhinoplasty. Aesthetic Plast Surg 2005;29:230-39

6. Steiger JD, Baker SR. Nuances of profile management: the radix. Facial Plast Surg Clin North Am 2009;17:15-28, v

7. Cervelli V, Bottini DJ, Gentile P. Reconstruction of the nasal tip. J Craniofac Surg 2007;18:1380-84
8. Bohluli B, Moharamnejad N, Bayat M. Dorsal hump surgery and lateral osteotomy. Oral Maxillofac Surg Clin North Am 2012;24: 75-86

9. Giacomarra V, Russolo M, Arnez ZM, et al. External osteotomy in rhinoplasty. Laryngoscope 2001;111:433-38

10. Daniel RK, Ethier R. Rhinoplasty: a CT-scan analysis. Plast Reconstr Surg 1987;80:175-84

11. Kim WS, Kim CH, Yoon JH. Premaxillary augmentation using autologous costal cartilage as an adjunct to rhinoplasty. J Plast Reconstr Aesthet Surg 2010;63:e686-90

12. Kim WS, Kim CH, Yoon JH. Premaxillary augmentation using autologous costal cartilage as an adjunct to rhinoplasty. J Plast Reconstr Aesthet Surg 2010;63:e686-90

13. Waite PD. Internal septorhinoplasty technique. Oral Maxillofac Surg Clin North Am 2012;24:109-17

14. Dresner HS, Hilger PA. An overview of nasal dorsal augmentation. Semin Plast Surg 2008;22:65-73

15. Brenner MJ, Hilger PA. Grafting in rhinoplasty. Facial Plast Surg Clin North Am 2009;17:91-113, vii

16. Gentile P, Cervelli V. Nasal dorsum reconstruction with 11th rib cartilage and auricular cartilage grafts. Ann Plast Surg 2009;62:63-66

17. Bottini DJ, Gentile P, Donfrancesco A, et al. Augmentation rhinoplasty with autologous grafts. Aesthetic Plast Surg 2008;32:136-42

18. Erol OO. The Turkish delight: a pliable graft for rhinoplasty. Plast Reconstr Surg 2000;105:2229-41, discussion 2242-43

19. Breadon GE, Kern EB, Neel HB 3rd. Autografts of uncrushed and crushed bone and cartilage: experimental observations and clinical implications. Arch Otolaryngol 1979;105:75-80

20. Schatz CJ, Ginat DT. Imaging of cosmetic facial implants and grafts. AJNR Am J Neuroradiol 2013;34:1674-81

21. Conrad K, Torgerson CS, Gillman GS. Applications of Gore-Tex implants in rhinoplasty reexamined after 17 years. Arch Facial Plast Surg 2008;10:224-31

22. Skouras A, Skouras G, Karypidis D, et al. The use of Medpor alloplastic material in rhinoplasty: experience and outcomes. J Plast Reconstr Aesthet Surg 2012;65:35-42

23. Inanli S, Sari M, Baylancicek S. The use of expanded polytetrafluoroethylene (Gore-Tex) in rhinoplasty. Aesthetic Plast Surg 2007;31:345-48

24. Erlich MA, Parhiscar A. Nasal dorsal augmentation with silicone implants. Facial Plast Surg 2003;19:325-30

25. Berghaus A, Stelter K. Alloplastic materials in rhinoplasty. Curr Opin Otolaryngol Head Neck Surg 2006;14:270-77

26. Humphrey CD, Arkins JP, Dayan SH. Soft tissue fillers in the nose. Aesthet Surg J 2009;29:477-84

27. Siclovan HR, Jomah JA. Injectable calcium hydroxylapatite for correction of nasal bridge deformities. Aesthetic Plast Surg 2009;33:544-48

28. Ginat DT, Schatz CJ. Imaging features of midface injectable fillers and associated complications. AJNR Am J Neuroradiol. 2013;34:1488-95

29. Murphy J, Marshall AH, Jones NS. Restoration of the impacted nasal pyramid using a Kirschner wire. J Laryngol Otol 2004;118:543-45

30. Gunter JP, Cochran CS. Management of intraoperative fractures of the nasal septal "L-strut": percutaneous Kirschner wire fixation. Plast Reconstr Surg 2006;117:395-402

31. Sarifakioglu N, Cigsar B, Aslan G. K-wire: a simple and safe method for internal stabilization of costal cartilage in L-strut grafts. Ann Plast Surg 2002;49:444

32. Barat M, Shikowitz MJ. Nasofrontal abscess following rhinoplasty. Laryngoscope 1985;95:1523-25

33. Graham BS, Thiringer JK, Barrett TL. Nasal tip ulceration from infection and extrusion of a nasal alloplastic implant. J Am Acad Dermatol 2001;44:362-64

34. Herbst A. Extrusion of an expanded polytetrafluoroethylene implant after rhinoplasty. Plast Reconstr Surg 1999;104:295-96

35. Bravo FG, Schwarze HP. Closed-open rhinoplasty with extended lip 
dissection: a new concept and classification of rhinoplasty. Plast Reconstr Surg 2008;122:944-50

36. Sykes JM, Tapias V, Kim JE. Management of the nasal dorsum. Facial Plast Surg 2011;27:192-202

37. Lam SM, Williams EF 3rd. Anatomic considerations in aesthetic rhinoplasty. Facial Plast Surg 2002;18:209-14

38. Araco A, Gravante G, Gentile P, et al. Iatrogenic collapse of the nasal valve after aesthetic rhinoplasty. Scand J Plast Reconstr Surg Hand Surg 2007;41:293-96
39. Holt GR, Garner ET, McLarey D. Postoperative sequelae and complications of rhinoplasty. Otolaryngol Clin North Am 1987;20:853-76

40. Poetker DM, Rhee JS, Mocan BO, et al. Computed tomography technique for evaluation of the nasal valve. Arch Facial Plast Surg 2004;6:240-43

41. Suh MW, Jin HR, Kim JH. Computed tomography versus nasal endoscopy for the measurement of the internal nasal valve angle in Asians. Acta Otolaryngol 2008;128:675-79

42. Fischer H, Gubisch W. Nasal valves-importance and surgical procedures. Facial Plast Surg 2006;22:266-80 